OPEN ACCESS

Edited by:

Xiangqian Guo,

Henan University, China

Reviewed by:

Chengqi Xu,

Huazhong University of Science and

Technology, China

Yu Zhangy,

Northeast Normal University, China

*Correspondence:

Tongtong $\mathrm{Ge}$

gett@mails.jlu.edu.cn

Specialty section:

This article was submitted to

Cancer Immunity

and Immunotherapy,

a section of the journal

Frontiers in Immunology

Received: 23 June 2021

Accepted: 18 August 2021

Published: 10 September 2021

Citation:

Wang Y, Sheng J, Chai J, Zhu C, Li X, Yang W, Cui $R$ and Ge T (2021)

Filamentous Bacteriophage-A Powerful Carrier for Glioma Therapy.

Front. Immunol. 12:729336. doi: 10.3389/fimmu.2021.729336

\section{Filamentous Bacteriophage-A Powerful Carrier for Glioma Therapy}

\author{
Yicun Wang, Jiyao Sheng, Jin Chai, Cuilin Zhu, Xin Li, Wei Yang, \\ Ranji Cui and Tongtong Ge*
}

Jilin Provincial Key Laboratory on Molecular and Chemical Genetic, The Second Hospital of Jilin University, Changchun, China

Glioma is a life-threatening malignant tumor. Resistance to traditional treatments and tumor recurrence present major challenges in treating and managing this disease, consequently, new therapeutic strategies must be developed. Crossing the blood-brain barrier (BBB) is another challenge for most drug vectors and therapy medications. Filamentous bacteriophage can enter the brain across the BBB. Compared to traditional drug vectors, phage-based drugs offer thermodynamic stability, biocompatibility, homogeneity, high carrying capacity, self-assembly, scalability, and low toxicity. Tumor-targeting peptides from phage library and phages displaying targeting peptides are ideal drug delivery agents. This review summarized recent studies on phage-based glioma therapy and shed light on the developing therapeutics phage in the personalized treatment of glioma.

Keywords: filamentous bacteriophage, glioma, target peptide, antibody, BBB, BBTB

\section{INTRODUCTION}

Glioma is the most common cerebral malignancy with high morbidity and mortality. Despite the current treatment measures such as surgery, radiation, and chemotherapy, the prognosis and mortality of patients has not improved significantly $(1-3)$. The annual death rate in China is as high as 30,000. Currently, the adverse reactions to glioma drugs are more prominent, and drug resistance is readily developed $(1,4,5)$. To overcome the limits of existing therapies, there is a pressing need for a treatment strategy that can selectively target cancer tissues and avoid non-target tissues.

In addition, the blood-brain barrier (BBB) is a formidable obstacle for the transport of most administered therapeutics to the brain $(6,7)$, and most anti-tumor drugs have difficulty passing the $\mathrm{BBB}$ and the blood-brain tumor barrier (BBTB), it is a major hurdle in the development of targeted drugs for glioma (8-10). Therefore, choosing a carrier that can pass through the BBB is very important for glioma treatment.

Filamentous bacteriophages (Ff phage) are nano-scale viruses that infect bacteria and are not harmful to humans (11-13). Ff phage fd, M13, and f1 are stable under harsh conditions and can be manufactured with uniform specifications and low cost (14-17). As well, Ff phage has genetic flexibility. In 1985, Smith et al. reported phage display technology to display a variety of proteins, antibodies, and peptides on the phage coat proteins. Subsequently, phage display libraries were injected intravenously into laboratory animals to screen the targeting peptides (18). Moreover, Ff phage could enter the central nervous system (CNS) without visible toxic effects $(19,20)$, it can pass through the $\mathrm{BBB}$ as a drug carrier, when administered intranasally or through convection-enhanced delivery (CED), and has great research potential for the treatment of brain diseases (21-24). 
Furthermore, the phage display library is used quickly and directly to screen peptides targeting tumor and anti-tumor antibodies. To date, there are numerous studies by the phage library screening tumor targeting peptides for target therapy and immunotherapy (25-27), and it has established the method for screening glioma targeting peptides across the $\mathrm{BBB}$, guiding the immunotherapy in patients. These phages and peptides targeting glioma cells could avoid or reduce the toxic effects of anti-cancer drugs (28-31). At the same time, phages, carrying targeted peptides and antibodies, stimulate the immune response and play an immunotherapy role $(28,32-35)$.

In summary, this review will clarify the strategy for applying Ff phage nanoparticles to glioma treatment. It can be used to direct clinical treatment of tumors and provide new ideas for personalized disease therapy.

\section{BIOPANNING THE TUMOR-TARGETED PEPTIDE}

Ff phage is a biological nanomaterial with a length of about $1 \mathrm{um}$ and a diameter of about $7 \mathrm{~nm}(14,36)$. It could specifically infect bacteria and is present in the human body and harmless to humans. Ff phage is made of single-stranded circular DNA and coat proteins. The main coat protein PVIII is located on the phage side and minor coat proteins (pIII, pV I, pVII, and pIX) are located at both tips (Figure 1).

Phage display is to insert the DNA sequence of the exogenous peptide into the phage coat protein gene and express the peptide on the surface of the phage along with the expression of the coat protein. The phage displaying peptide still has protein assembly and infection activity (37-39). Based on phage display technology, phage libraries were built and used to select targeting phages, such as tumor-targeted peptides, which improved research efficiency and reduced costs. In addition, these targeted peptides developed functions of cell-targeting, tumor-homing, and cell-penetrating (40-42). Phage libraries were usually screened by using molecules, cells, and tissues in vitro or in animals and human patients $(38,43,44)$.

Traditional chemotherapeutics have poor accuracy on tumor cells and are prone to adverse reactions. Therefore, the targeted therapy is particularly important for tumor therapy (45-47). Peptides specifically binding to tumor tissues, as carriers to direct drugs to tumor tissues, significantly improved the accuracy of drug targeting (48-51). Although monoclonal antibodies as vectors were successfully applied to anti-tumor, the high molecular weight of antibodies might reduce efficiency (52-55), while the phage peptide library has the benefits of screening for small molecular weight peptides, which can compensate for antibody deficiencies that are widely used in the diagnosis and treatment of glioma.

The screened peptides could combine with markers for imaging. Wang et al. developed an HO-8910 ovarian cancer cell targeting peptide (NPMIRRQ) from the phage library, which demonstrated the ability to selectively bind ovarian cancer cells using immunofluorescence and immunohistochemical assays (56).

The screened peptides could also couple with chemotherapeutic drugs or some gene, and then be used in the tumor-targeted treatment or gene treatment; Du et al. obtained the A54 peptide (AGKGTPSLETTP) by in vivo phage display for hepatocarcinoma and conjugated it with doxorubicin for in vivo targeted therapy. The study showed the A54-doxorubicin reduced the tumor size and prolongated the long-term survival rate (57).

Furthermore, some specific binding peptides that inhibit tumor growth, invasion, and metastasis, could be used to treat tumors directly. Zhou et al. isolated the peptide, SWQIGGN, from a Ph.D.-C7C phage library with the ovarian cancer cell HO8910 (58). They found that the peptide controlled cancer cell migration, viability, adhesion capacity, invasion, and tumor growth in vivo.

Currently, the screening of tumor-targeted peptides is widely used in targeting the treatment of tumors, such as lung cancer, stomach cancer, liver cancer, colon cancer, and prostate cancer.

\section{FF PHAGE, A TARGETED THERAPY VECTOR}

Poor permeability of the cellular plasma membrane to a drug or gene is the main barrier for targeted delivery, while the nature of vectors affects the efficiency of drug delivery in tumors and tumor-affected tissues. Therefore, construction and selection of drug vectors is one of the most important steps of tumor therapy. Ff phage could deliver genes and peptides to mammalian cells, and the structure of Ff phage results in more efficient cellular attachment and ensuing membrane penetration. It has been

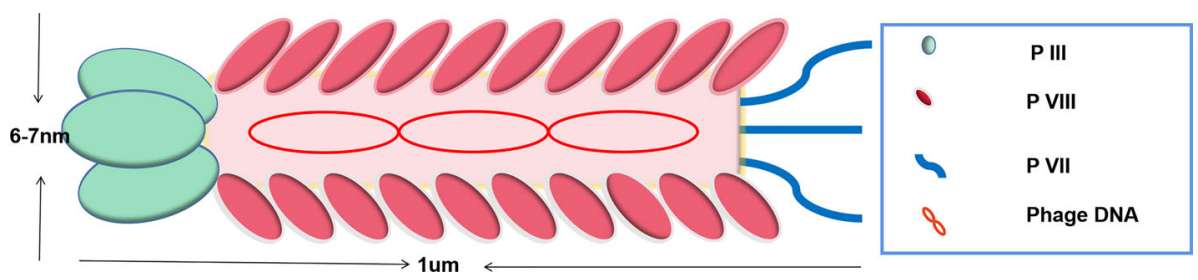

FIGURE 1 Schematic of Ff phage. Phage consists of a tubular protein coat surrounding a single-stranded circular DNA. Proteins III and VII are the minor coat proteins, present in 3-5 copies. Protein VIII is the major phage coat protein and presents in 2700 copy numbers. 
successfully used in treatment under the U.S. Food and Drug Administration (FDA) process (www.fda.gov), and methods for isolating, storing, and producing phages are now becoming more available and better developed under the ATCC (www.atcc.org) and PHE (www.gov.uk/government/organisations/publichealth-england) collections.

Ff phage might be an ideal carrier for drug therapy and immunotherapy. First, an exogenous gene could be inserted into the Ff phage genome. Meanwhile, the peptide displayed on the Ff phage presents its natural conformation and the phage has a strong resistance to physical and chemical factors (59-61). Second, the phage displayed exogenous peptides or chemical modifications, which could combine with inorganic nanomaterials/drugs, to form phage-nanocomplexes and drugloaded phages. It is well utilized in photodynamic cancer therapy (62-64). Some researchers used the Fd phage to display a cancertargeting peptide on pVIII major coat protein, and then conjugated photosensitizer at the $\mathrm{N}$-terminal end of the targeting peptides, and demonstrated that the complex of phage-photosensitizers was able to selectively target and kill SKBR3 tumor cells in vitro (65). Third, the displayed Ff phage triggers every arm of the immune response. Berardinis et al. engineered fd to target mouse dendritic cells (DCs), and activated the innate and adaptive responses without the need of exogenous adjuvants (66). The study has also shown that phage could induce the IL- 2 and IFN- $\gamma$ cytokines, which were useful in tumor immunotherapy (67). Fourth, drug conjugated phage increases the half-life in the blood steam (68), while the toxicity and side effects of hazardous drugs are reduced in combination with the Ff phage.

In a word, Ff phage, as a carrier of therapeutic reagents, has more advantages in targeted therapy, with high specificity, high sensitivity, and reproducibility.

\section{THE APPLICATION OF PHAGE NANOMATERIALS TO GLIOMA THERAPY}

Gliomas are aggressive brain tumors and challenging therapeutic cancers that have high mortality (69). The 5-year survival rate of glioma is very low (70), and the prognosis of glioblastoma patients is poor with a median survival of less than 1 year. Recently, cancer research in the U.K. showed that $40 \%$ of brain tumor patients survive their cancer for 1 year and more than $10 \%$ survive their cancer for 5 years or more.

At present, the clinical therapies for gliomas are surgical therapy, radiation therapy, chemotherapy, gene therapy, and other comprehensives $(1,71-74)$. However, it is easy to relapse after these treatments, and the patients' survival rates are not significantly improved. Immunotherapy is useful for treating tumors, the mAbs bevacizumab, rituximab, and trastuzumab were already widely used against tumors outside the brain (7579). But the current immunotherapy for medical glioma is costly and inefficient.

$\mathrm{BBB}$ is another significant barrier to the delivery of targeted treatments for brain tumors. Indeed, more than $98 \%$ of low- molecular-weight candidate drugs and almost $100 \%$ of large therapeutic candidate drugs cannot cross the BBB (80). There is an urgent need for a carrier that carries drugs across the BBB. Phage display technology can be used for the construction of peptide libraries to screen for glioma tumor-targeting peptides and peptides across the BBB. Surface functionalization with these peptides is a sophisticated way to develop drug delivery platforms that cross the $\mathrm{BBB}$ and target glioma.

\section{Identification of Targeting Peptide and Antibody}

About $30 \%$ of all human antibody therapies are derived from phage antibody libraries. In addition, the screening of phage display libraries is an effective tool to obtain peptides that target glioma tumors both in vitro and in vivo $(43,49,81,82)$.

\section{In Vitro Panning}

In vitro panning was used to identify peptides that specifically bind to glioma cells and proteins. Ho et al. isolated GL1 peptide that specifically interacts with primary glioma cells obtained from human biopsy specimens using a phage library and injected the GL1-bearing phages into a mouse (83). They found that the phage targeted the mouse brain tumor and this peptide had the potential to be used for therapeutics to glioma cells.

Glioma stem cells (GSCs) are the major drivers of brain tumors. Beck et al. screened the peptides binding to GSCs from the phage display library, and the administration of GSC-homing peptide into the glioma mice model resulted in penetration into the brain and specific accumulation in glioma. CD133 is a cell surface antigen allowing identification of GBMs. Yoon et al. screened the peptides targeted CD133 from U373 glioma cells, using the phage library, and conjugated the targeting peptide (CBP4) to GNPs. They found that the targeting peptide was effective for passage into the brain extracellular space (84). The protein kinase $\mathrm{C}(\mathrm{PKC})$ family plays an important role in glioma, is a potential biomarker to disturb the expression of CD133 on glioma cells, and may have a therapeutic effect on GSCs. Yoon et al. also identified 12-amino-acid peptide-binding toward the PKCd catalytic domain through a phage display library and certificated that the peptide could target and inhibit PKC, provided a novel peptide sequence for a therapeutic strategy to target GSCs. To identify novel peptides targeting malignant gliomas, Wang et al. used a 12-mer peptide phage display library and obtained the peptide (VTWTPQAWFQWV) bound to U87MG cells. In addition, the VTW phage is bound strongly to other human glioma cell lines, including $\mathrm{H} 4$, SW1088, and SW1783 (85-87).

The discovery and isolation of antibodies are important for the treatment of glioblastoma (GBM). Insulin-like growth factor binding protein 2 (IGFBP2) is highly upregulated in GBM tissues and plays a crucial role in the invasion of glioma cells. Kondaiah et al. screened $s c F v$ phage display libraries using recombinant IGFBP2 and identified that scFv B7J could bind to IGFBP2 and inhibit the migration and invasion of glioma cells (88). Tumor sphere cells more closely resemble the phenotype of primary tumors than do serum-cultured cell lines. Liu et al. derived GBM 
tumorspheres from human brain tumor specimens, biopanning the scFvs that bind to CD133 positive GBM tumorsphere cells from scFvs phage library and indicated one scFvs could inhibit the growth of the GBM tumorsphere cells in vitro.

Overall, peptides targeting glioma were identified using phage display library in vitro. It is useful for further development of novel therapies that target glioma cells and provide novel diagnostic and therapeutic modalities for human brain malignancies.

\section{In Vivo Pannings}

In vivo pannings were successful in obtaining organ-specific targeting peptides in the animal model. Peptides and antibodies may be isolated, which recognize subsets of glioma tumors via in vivo biopanning of phage display libraries in glioma xenografts.

GBM displays cellular hierarchies with self-renewing gliomainitiating cells (GICs) at the apex. To discover new GIC targets Rich et al. delivered a phage peptide library intravenously to a GBM xenograft in vivo, then derived GICs, and then identified the peptides targeting VAV3 and CD97. These peptides could be used for identifying and targeting of GICs (89),

Additional destruction of existing tumor vasculature effectively deprives tumors from blood. With the need to identify novel tumor vascular targeting agents, Lith et al. identified a nanobody $\mathrm{C}-\mathrm{C} 7$ in vivo biopanning of phage display library in an orthotopic mouse model of diffuse glioma, which showed that $\mathrm{C}-\mathrm{C} 7$ recognized a subpopulation of tumor blood vessels in glioma xenografts and clinical glioma samples (90). Leenders et al. cloned a nanobody phage library from lymphocytes of a llama, which had been immunized with clinical glioma tissue and isolated the nanobodies discriminated incorporated pre-existent vessels in highly infiltrative cerebral E434 xenografts from normal brain vessels via biopanning in vivo with this library in the orthotopic glioma xenograft models (91).

In vivo biopanning, in appropriate animal models, is a very promising approach for future identifying novel molecular tools for targeting glioma tumors and oncogenic pathways preferentially activated within the tumor hierarchy, which could offer a new strategy for the development of glioma therapy.

\section{Development of Carriers for Targeted Drug Delivery}

The $\mathrm{BBB}$ and $\mathrm{BBTB}$ restrict the entry of drugs given routinely with glioma $(92,93)$. Thus, effective glioma treatment requires therapeutic agents to penetrate both $\mathrm{BBB}$ and BBTB. An emerging solution consists of identifying the peptide vectors that penetrate the $\mathrm{BBB} / \mathrm{BBTB}$.

In recent years, numerous studies have focused on modifying the pharmacokinetics of chemotherapeutic drugs by using a delivery vector or by adding targeting properties. Langel et al. developed a tumor-targeted delivery vector gHoPe2 that is based on a cell-penetrating peptide $\mathrm{pVEC}$ and a novel glioma-targeting peptide sequence gHo (NHQQQNPHQPPM), which was identified using phage display technology. The vector could be efficiently absorbed into glioma cells and xenograft glioma tumors in a mouse model. In addition, vectored doxorubicin was more effective than free drug in a mouse glioma xenograft model (94). The study demonstrated the general feasibility of the current approach for constructing targeted delivery systems based on the cell-penetrating peptides.

The BBTB is formed by brain tumor capillaries and comprises a barrier that is variably distinct from the $\mathrm{BBB}$, forming an additional hurdle toward treatment. Lin et al. identified a novel BBB/BBTB-penetrating peptide M1 (TFYGGRPKRNNFLRGIR) from the phage displayed peptide library in vivo and modified the M1 peptide with a tumor-targeting named M1-RGD (TFYGGRPKRNNFLRGIRRGD), then they conjugated the MIRGD with drug and applied PDC M1-RGD-PTX to treat glioma and found that it suppressed glioma proliferation and thus extended mouse survival in a glioma xenograft model (95). The study suggested that the peptide M1 could serve as a vector through the $\mathrm{BBB}$ and $\mathrm{BBTB}$.

Therefore, the targeting peptides screening from the phage library are effective drug carriers across the BBB and BBTB, and phage display technology has wide applications for treating brain tumors.

\section{FF PHAGE: A POTENTIAL THERAPEUTIC VEHICLE FOR GLIOMAS}

The rod-shaped nanoparticles have higher avidity and selectivity for endothelial cells and increase the specificity and vascular targeting for brain endothelium (96). Increasing the length-todiameter ratio of $\mathrm{Ff}$ phage results in more effective cellular attachment and ensuing membrane penetration. The phage maintains the biological activity of the peptide displayed on the phage vector, these properties make Ff phage suitable for use as a vector in the treatment of central nervous diseases (97), and research proved that phages carrying antibodies effectively label $\mathrm{A} \beta$ plaques is an efficient and nontoxic delivery vector to the brain and is useful for the treatment of Alzheimer's disease in vivo (68).

\section{Ff Phage Could Deliver the Drug to the CNS}

The function of BBB is under normal in low-grade glioma (98), Ff phage can pass the $\mathrm{BBB}$ and deliver therapeutics directly to the CNS when administered intranasally. It has been applied on protein-based treatments for other drug abuse syndromes. Janda et al. demonstrated that Ff phage displaying cocaine-binding proteins sequester cocaine in the brain and blocked the psychoactive effects of cocaine administered intranasally (23). Additionally, Ff phages have been reported to possess antitumorigenic properties. The researchers found that Ff phages could even inhibit the growth of subcutaneous GBM tumors in mice and this activity was mediated in part by lipopolysaccharide molecules attached to virion using the intranasal route.

Convection-enhanced delivery (CED) is a novel approach for administering chemotherapy in patients with brain tumors (99, 100). Additionally, CED is also an effective and safe method for 
distributing M13 phage to the brain (97). It reminds us that Ff phage could deliver the medicine to glioma via CED.

Normal vascular function is disturbed in high-grade glioma and $\mathrm{Ff}$ phage has more capacity to cross the $\mathrm{BBB}$ through various routes. Based on Ff phage, a functional dual vector could target and treat glioma intravenously. Hajitou et al. have designed a hybrid AAV/phage with a recombinant adeno-associated virus genome (rAAV) and the capsid of M13 phage as a vector for dual targeting of therapeutic genes to glioblastoma. The phage capsid displayed the RGD4C ligand that binds the $\alpha v \beta 3$ integrin receptor and the recombinant $\mathrm{rAAV}$ genes expressed from a tumor-activated and temozolomide (TMZ)-induced promoter of the glucose-regulated protein, Grp78 (101). The recombinant vector targeted intracranial tumors in mice following intravenous administration and the gene delivered was expressed in human GBM cells. The construction of a double display Ff phage system was also reported. Sandlie and his team also developed a P III/P VII phage-genome double display system that could simultaneously carry two different exogenous peptides to perform different biological functions (102), and we can infer that the double display phage displayed targeting peptide and antibody could apply for treating glioma.

Taken together, Ff phages have the anti-tumor capability and could be genetically modified to display tumor homing motifs and conjugated to cytotoxic drugs. These phages are harmless when administered intranasally, CED, or intravenously and may present route anti-tumorigenic. Using them as vectors could be useful in the treatment of glioma.

\section{Future Prospects for Personalized Therapy}

Glioma is a highly heterogeneous disease with major molecular differences in the expression of tumor cell surface markers in patients with the same grade of cancer (103). Currently, drugs used for glioma are often toxic to normal cells, resulting in serious side effects (104-106), and the broad range of drugs should be improved, as glioma cells are also prone to drug resistance $(107,108)$ Therefore, personalized therapy is very critical for gliomas.

Extensive research has used the phage display library to identify tumor-specific ligands by panning established tumor cell lines in vitro or by panning in an animal model. However, the material derived from the patient has more advantages of clinical relevance. It is tolerable in the human body, several groups have injected Ff phage library into patients without obvious side effects, and it is highly successful to develop a protocol for selecting phage displayed ligands in patients (109, 110). Shukla et al. conducted the toxicity profiles of different doses and phage displayed library formats for cancer patients (111). Then, they obtained and evaluated the tumor-homing phage-antibodies and derived soluble scFv antibodies to patients' tumors and found that these antibodies were cancer-specific (112). Moreover, Ff phages are stable. They retain infectivity after IV injection and circulation in the human body. These studies remind us that phage display technology can be used to identify tumor-specific ligands to develop personalized therapy.

Therefore, in theory, phage display strategies can achieve success when applied to target glioma cells for personalized treatments. Because of the specificity of biomarkers, glioma patients could be administered using phage display libraries and profiled for the presence of cancer targets before treatment. Such cancer-specific peptides can also be obtained from individual cancer patients in vitro and then be designed to target cancer treatment for personalized treatments (Figure 2).

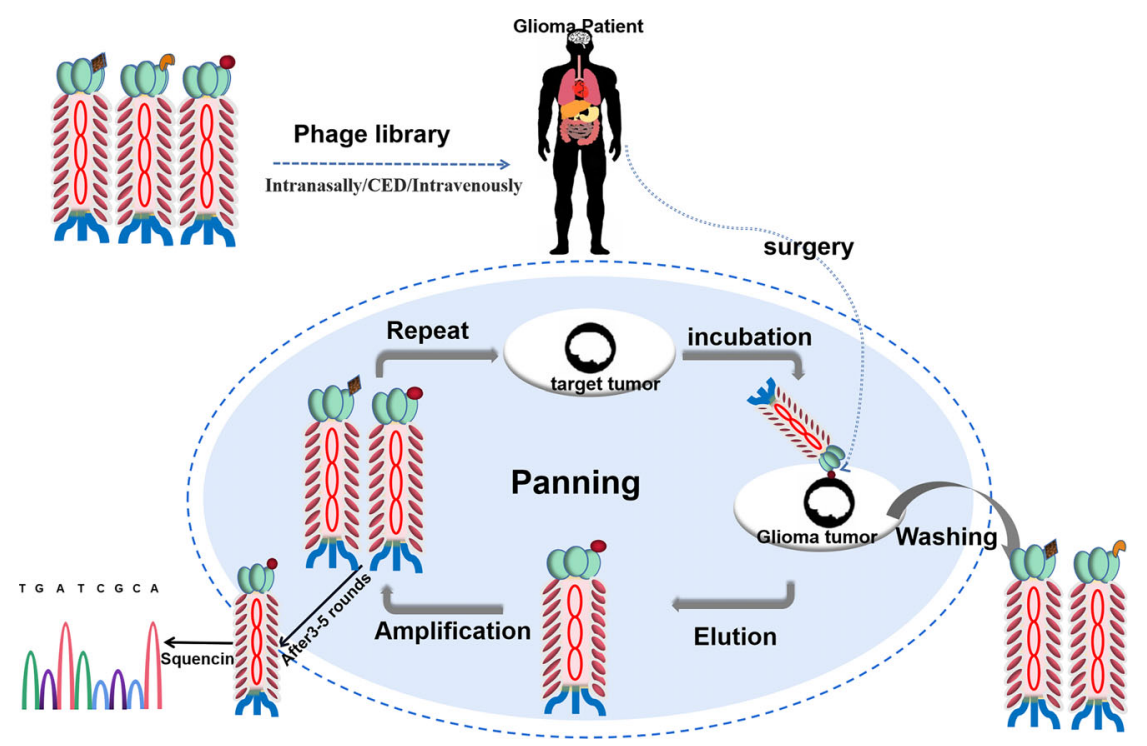

FIGURE 2 | Schematic of affinity-selection of targets-binding phages from a phage library for personalized therapy of glioma. An antibody phage library is administered in glioma patients. After incubation, get the tumor from the patient. The unbound phages are washed and the bound phages are collected and amplified. After $3-5$ rounds, the affinitive phages are enriched and sequenced. 


\section{CONCLUSION}

Gliomas are the most common primary brain tumors. Effective treatment of glioma is hampered by the presence of both $\mathrm{BBB}$ and BBTB. In this review, we presented an Ff phage approach to enhance the permeability of drugs through BBB and BBTB.

Although Ff phages have the problem of further optimization and improvement in separation and purification, they also have a number of advantages. Ff phage has a greater level of safety, it is not reproduce naturally in mammalian hosts, and it expresses a wide range of peptides on coat proteins using genetic engineering techniques to attach targeting peptides and antibodies.

Phage display is a high throughput screening strategy to construct peptide libraries that are used to screen glioma targeting peptides. These peptides might cross the BBB/BBTB and target tumors. It can also be used as a drug or drug carrier after being modified. Furthermore, Ff phage is an ideal transport carrier to CNS across the BBB, it has the anti-tumor ability and could be genetically modified to display glioma homing motifs and conjugated to cytotoxic drugs. Moreover, Ff phage displaying targeting peptide has stronger tumor penetrating ability, a higher load of drug delivery ability, and lower toxicity.

Developing carrier-based Ff phage as a drug delivery system can solve the problem of going through the BBB and BBTB.

\section{REFERENCES}

1. Roshdy E, ElNaggar M, Atta H, Kandeel A, Abdel-Wanis M, Abd Elbadee OM, et al. Role of Post-Therapy Tc-99m-MIBI Single-Photon Emission Computed Tomography/Computed Tomography Scan in Predicting Survival in Patients With High-Grade Glioma. Nucl Med Commun (2021) 42(6):625-32. doi: 10.1097/Mnm.0000000000001385

2. Wang J, Tang W, Yang M, Yin Y, Li H, Hu FF, et al. Inflammatory Tumor Microenvironment Responsive Neutrophil Exosomes-Based Drug Delivery System for Targeted Glioma Therapy. Biomaterials (2021) 273:120784. doi: 10.1016/j.biomaterials.2021.120784

3. Zhang JH, Chen H, Chen C, Liu HM, He YR, Zhao JL, et al. Systemic Administration of Mesenchymal Stem Cells Loaded With a Novel Oncolytic Adenovirus Carrying IL-24/Endostatin Enhances Glioma Therapy. Cancer Lett (2021) 509:26-38. doi: 10.1016/j.canlet.2021.03.027

4. Rao V, Cheruku SP, Manandhar S, Vibhavari RJA, Nandakumar K, Rao $\mathrm{CM}$, et al. Restoring Chemo-Sensitivity to Temozolomide via Targeted Inhibition of Poly (ADP-Ribose) Polymerase-1 by Naringin in Glioblastoma. Chem Papers (2021) 75:4861-71. doi: 10.1007/s11696021-01700-0

5. Cao YQ, Chai WY, Wang YG, Tang D, Shao DCA, Song H, et al. lncRNA TUG1 Inhibits the Cancer Stem Cell-Like Properties of TemozolomideResistant Glioma Cells by Interacting With EZH2. Mol Med Rep (2021) 24 (1):533. doi: 10.3892/Mmr.2021.12172

6. Lo YL, Lin HC, Hong ST, Chang CH, Wang CS, Lin AMY. Lipid Polymeric Nanoparticles Modified With Tight Junction-Modulating Peptides Promote Afatinib Delivery Across a Blood-Brain Barrier Model. Cancer Nanotechnology (2021) 12(1):13. doi: 10.1186/S12645-021-00084-W

7. Haupt M, Bahr M, Doeppner TR. Lithium Beyond Psychiatric Indications: The Reincarnation of a New Old Drug. Neural Regeneration Res (2021) 16 (12):2383-7. doi: 10.4103/1673-5374.313015

8. Wang Y, Kong XQ, Wu F, Xu B, Bao DJ, Cheng CD, et al. SOCS1/JAK2/ STAT3 Axis Regulates Early Brain Injury Induced by Subarachnoid Hemorrhage via Inflammatory Responses. Neural Regeneration Res (2021) 16(12):2453-64. doi: 10.4103/1673-5374.313049

9. Lasri A, Sturrock M. The Influence of Methylation Status on a Stochastic Model of MGMT Dynamics in Glioblastoma: Phenotypic Selection Can
In short, Ff phage display technology is a powerful method of developing highly effective target drug delivery carriers. In addition, it opens the door to the development of personalized therapy agents in the future.

\section{AUTHOR CONTRIBUTIONS}

YW: Conceptualization; JS: Methodology and analysis; JC: Data Curation and analysis; CZ: Resources; XL: Visualization; WY: Writing; RC: Supervision; TG: Writing-Reviewing and Editing.

\section{FUNDING}

This study was supported by the grant from the National Key R\&D Program of China (Grant \#2018YFC1311600), National Natural Science Foundation of China (81901880), Natural Science of Science and Technology Division Jilin (20200201505JC and 20190103099JH), Education deparment research project of Jilin (JJKH20201016KJ)and program of Jilin finance deparment (2019SRCJ003). Jilin provincial health project (2020SC2T091).

Occur With and Without a Downshift in Promoter Methylation Status. $J$ Theor Biol (2021) 521:110662. doi: 10.1016/J.Jtbi.2021.110662

10. Inglut CT, Gray KM, Vig S, Jung JW, Stabile J, Zhang YJ, et al. Photodynamic Priming Modulates Endothelial Cell Cell Junction Phenotype for Light-Activated Remote Control of Drug Delivery. IEEE J Sel Top Quantum Electron (2021) 27(4):7200311. doi: 10.1109/ Jstqe.2020.3024014

11. Gonzalez-Mora A, Hernandez-Perez J, Iqbal HMN, Rito-Palomares M, Benavides J. Bacteriophage-Based Vaccines: A Potent Approach for Antigen Delivery. Vaccines (2020) 8(3):504. doi: 10.3390/Vaccines8030504

12. Chung J, Jung Y, Hong C, Kim S, Moon S, Kwak EA, et al. Filamentous AntiInfluenza Agents Wrapping Around Viruses. J Colloid Interf Sci (2021) 583:267-78. doi: 10.1016/j.jcis.2020.09.012

13. Margot S, Saulnier A, Barban V. Phages and Vaccination: Towards New Opportunities? Virologie (2020) 24(1):37-47. doi: 10.1684/vir.2019.0794

14. Marvin DA, Welsh LC, Symmons MF, Scott WRP, Straus SK. Molecular Structure of Fd (F1, M13) Filamentous Bacteriophage Refined With Respect to X-Ray Fibre Diffraction and Solid-State NMR Data Supports Specific Models of Phage Assembly at the Bacterial Membrane. J Mol Biol (2006) 355 (2):294-309. doi: 10.1016/j.jmb.2005.10.048

15. Jamaledin R, Sartorius R, Di Natale C, Vecchione R, De Berardinis P, Netti PA. Recombinant Filamentous Bacteriophages Encapsulated in Biodegradable Polymeric Microparticles for Stimulation of Innate and Adaptive Immune Responses. Microorganisms (2020) 8(5):650. doi: 10.3390/microorganisms 8050650

16. Sattarl S, Bennettl NJ, Wen WX, Guthrie JM, Blackwell LF, Conway JF, et al Ff-Nano, Short Functionalized Nanorods Derived From Ff (F1, Fd, or M13) Filamentous Bacteriophage. Front Microbiol (2015) 6:316. doi: 10.3389/ Fmicb.2015.00316

17. Rakonjac J, Russel M, Khanum S, Brooke SJ, Rajic M. Filamentous Phage: Structure and Biology. Recombinant Antibodies Infect Dis (2017) 1053:1-20. doi: 10.1007/978-3-319-72077-7_1

18. Smith GP. Phage Display: Simple Evolution in a Petri Dish (Nobel Lecture). Angewandte Chemie-International Edition (2019) 58(41):14428-37. doi: 10.1002/anie. 201908308

19. Staquicini FI, Smith TL, Tang FHF, Gelovani JG, Giordano RJ, Libutti SK, et al. Targeted AAVP-Based Therapy in a Mouse Model of Human Glioblastoma: A 
Comparison of Cytotoxic Versus Suicide Gene Delivery Strategies. Cancer Gene Ther (2020) 27(5):301-10. doi: 10.1038/s41417-019-0101-2

20. Zhou X, Smith QR, Liu XL. Brain Penetrating Peptides and Peptide-Drug Conjugates to Overcome the Blood-Brain Barrier and Target CNS Diseases. Wiley Interdiscip Rev Nanomed Nanobiotechnol (2021) 13(4):e1695. doi: 10.1002/Wnan.1695

21. Wan XM, Chen YP, Xu WR, Yang WJ, Wen LP. Identification of Nose-toBrain Homing Peptide Through Phage Display. Peptides (2009) 30(2):34350. doi: 10.1016/j.peptides.2008.09.026

22. Dabrowska K. Phage Therapy: What Factors Shape Phage Pharmacokinetics and Bioavailability? Systematic Crit review Medicinal Res Rev (2019) 39 (5):2000-25. doi: 10.1002/med.21572

23. Carrera MRA, Kaufmann GF, Mee JM, Meijler MM, Koob GF, Janda KD. Treating Cocaine Addiction With Viruses. Proc Natl Acad Sci USA (2004) 101(28):10416-21. doi: 10.1073/pnas.0403795101

24. Hua YF, Luo TT, Yang YQ, Dong D, Wang R, Wang YJ, et al. Phage Therapy as a Promising New Treatment for Lung Infection Caused by CarbapenemResistant Acinetobacter Baumannii in Mice. Front Microbiol (2018) 8:2659. doi: 10.3389/Fmicb.2017.02659

25. Minenkova O, Pucci A, Pavoni E, De Tomassi A, Fortugno P, Gargano N, et al. Identification of Tumor-Associated Antigens by Screening PhageDisplayed Human cDNA Libraries With Sera From Tumor Patients. Int $J$ Cancer (2003) 106(4):534-44. doi: 10.1002/ijc.11269

26. Barth S, Weidenmuller U, Tur MK, Schmidt MFG, Engert A. Combining Phage Display and Screening of cDNA Expression Libraries: A New Approach for Identifying the Target Antigen of an $\mathrm{scFv}$ Preselected by Phage Display. J Mol Biol (2000) 301(4):751-7. doi: 10.1006/jmbi.2000.4038

27. Sunderland KS, Yang MY, Mao CB. Phage-Enabled Nanomedicine: From Probes to Therapeutics in Precision Medicine. Angewandte ChemieInternational Edition (2017) 56(8):1964-92. doi: 10.1002/anie.201606181

28. Rahn JJ, Lun XQ, Jorch SK, Hao XG, Venugopal C, Vora P, et al. Development of a Peptide-Based Delivery Platform for Targeting Malignant Brain Tumors. Biomaterials (2020) 252:120105. doi: 10.1016/ j.biomaterials.2020.120105

29. Potez M, Kim J, She C, Chaudhary N, Liu J. In Vivo Phage Display Identifies Peptide Targeting N-Cadherin on Glioma Stem Cells. Neuro-Oncology (2020) 22:196-6. doi: 10.1093/neuonc/noaa215.819

30. Chen K, Yap LP, Park R, Hui XL, Wu KC, Fan DM, et al. A Cy5.5-Labeled Phage-Displayed Peptide Probe for Near-Infrared Fluorescence Imaging of Tumor Vasculature in Living Mice. Amino Acids (2012) 42(4):1329-37. doi: $10.1007 / \mathrm{s} 00726-010-0827-5$

31. Zhang MF, Chen XS, Ying M, Gao J, Zhan CY, Lu WY. Glioma-Targeted Drug Delivery Enabled by a Multifunctional Peptide. Bioconjugate Chem (2017) 28(3):775-81. doi: 10.1021/acs.bioconjchem.6b00617

32. Walsh L, Johnson CN, Hill C, Ross RP. Efficacy of Phage- and BacteriocinBased Therapies in Combatting Nosocomial MRSA Infections. Front Mol Biosci (2021) 8:654038. doi: 10.3389/Fmolb.2021.654038

33. Upadhaya SD, Ahn JM, Cho JH, Kim JY, Kang DK, Kim SW, et al. Bacteriophage Cocktail Supplementation Improves Growth Performance, Gut Microbiome and Production Traits in Broiler Chickens. J Anim Sci Biotechnol (2021) 12(1):49. doi: 10.1186/S40104-021-00570-6

34. Gembara K, Dabrowska K. Phage-Specific Antibodies. Curr Opin Biotechnol (2021) 68:186-92. doi: 10.1016/j.copbio.2020.11.011

35. Bichet MC, Chin WH, Richards W, Lin YW, Avellaneda-Franco L, Hernandez CA, et al. Bacteriophage Uptake by Mammalian Cell Layers Represents a Potential Sink That may Impact Phage Therapy. Iscience (2021) 24(4):102287. doi: 10.1016/J.Isci.2021.102287

36. Lubkowski J, Hennecke F, Pluckthun A, Wlodawer A. Filamentous Phage Infection: Crystal Structure of G3p in Complex With its Coreceptor, the CTerminal Domain of TolA. Structure (1999) 7(6):711-22. doi: 10.1016/ S0969-2126(99)80092-6

37. Huo JR, Zhang GA, Wang L, Sun WJ, Jia L, Yang XH, et al. Combining the Advantages of Prokaryotic Expression and T7 Phage Display Systems to Obtain Antigens for Antibody Preparation. Protein Expr Purif (2021) 184:105808. doi: 10.1016/J.Pep.2020.105808

38. Gomez-Arribas LN, Juste-Dolz A, Peltomaa R, Gimenez-Romero D, Morais $\mathrm{S}$, Barderas R, et al. Identification of High-Affinity Phage-Displayed VH Fragments by Use of a Quartz Crystal Microbalance With Dissipation
Monitoring. Sens Actuators B Chem (2021) 340:129954. doi: 10.1016/ J.Snb.2021.129954

39. Chen ZX, Mao XJ, Ye XH, Li SH, Wu TL, Wang Q, et al. A Novel and Biocompatible Nanofiber of VEGF Peptide for Enhanced Corneal Neovascularization Suppression. Chem Eng J (2021) 416:129081. doi: 10.1016/J.Cej.2021.129081

40. Wu LP, Ahmadvand D, Su JN, Hall A, Tan XL, Farhangrazi ZS, et al. Crossing the Blood-Brain-Barrier With Nanoligand Drug Carriers SelfAssembled From a Phage Display Peptide. Nat Commun (2019) 10:4635. doi: 10.1038/S41467-019-12554-2

41. Kim Y, Lillo AM, Steiniger SCJ, Liu Y, Ballatore C, Anichini A, et al. Targeting Heat Shock Proteins on Cancer Cells: Selection, Characterization, and Cell-Penetrating Properties of a Peptidic GRP78 Ligand. Biochemistry (2006) 45(31):9434-44. doi: 10.1021/bi060264j

42. Juliano RL, Alam R, Dixit V, Kang HM. Cell-Targeting and Cell-Penetrating Peptides for Delivery of Therapeutic and Imaging Agents. Wiley Interdiscip Rev Nanomed (2009) 1(3):324-35. doi: 10.1002/wnan.4

43. Wang $\mathrm{H}, \mathrm{Wu} \mathrm{ZC}, \mathrm{Hu} \mathrm{P}$, Ren HL, Li YS, Zheng Y, et al. Identification of Chicken-Derived scFv Against N-Glycolylneuraminic Acid Retrieved From an Immune Library by Phage Display. Protein Expr Purif (2021) 182:105841. doi: 10.1016/J.Pep.2021.105841

44. Eskafi AH, Bagheri KP, Behdani M, Yamabhai M, Shahbazzadeh D, KazemiLomedasht F. Development and Characterization of Human Single Chain Antibody Against Iranian Macrovipera Lebetina Snake Venom. Toxicon (2021) 197:106-13. doi: 10.1016/j.toxicon.2021.04.017

45. Panchal K, Sahoo RK, Gupta U, Chaurasiya A. Role of Targeted Immunotherapy for Pancreatic Ductal Adenocarcinoma (PDAC) Treatment: An Overview. Int Immunopharmacol (2021) 95:107508. doi: 10.1016/J.Intimp.2021.107508

46. Hall WA, Small C, Paulson E, Koay EJ, Crane C, Intven M, et al. Magnetic Resonance Guided Radiation Therapy for Pancreatic Adenocarcinoma, Advantages, Challenges, Current Approaches, and Future Directions. Front Oncol (2021) 11:628155. doi: 10.3389/Fonc.2021.628155

47. Corrigan L, Lowery M. Ivosidenib for the Treatment of Isocitrate Dehydrogenase1 Mutant Cholangiocarcinoma. Expert Rev Gastroenterol Hepatol (2021) 15 (5):475-81. doi: 10.1080/17474124.2021.1915765

48. Willimsky G, Beier C, Immisch L, Papafotiou G, Scheuplein V, Goede A, et al. In Vitro Proteasome Processing of Neosplicetopes Does Not Predict Their Presentation In Vivo. Elife (2021) 10:e62019. doi: 10.7554/eLife.62019

49. Sui Y, Zhu RJ, Hu W, Zhang W, Zhu HB, Gong M, et al. Phage Display Screening Identifies a Prostate Specific Antigen (PSA)(-/Lo) Prostate Cancer Cell Specific Peptide to Retard Castration Resistance of Prostate Cancer. Trans Oncol (2021) 14(3):101020. doi: 10.1016/J.Tranon.2021.101020

50. Ma YM, Dong YX, Li X, Wang F, Zhang Y. Tumor-Penetrating PeptideFunctionalized Ferritin Enhances Antitumor Activity of Paclitaxel. ACS Appl Bio Materials (2021) 4(3):2654-63. doi: 10.1021/acsabm.0c01613

51. Chongchai A, Waramit S, Suwan K, Al-Bahrani M, Udomruk S, Phitak T, et al. Bacteriophage-Mediated Therapy of Chondrosarcoma by Selective Delivery of the Tumor Necrosis Factor Alpha (TNF Alpha) Gene. FASEB J (2021) 35(5):e21487. doi: 10.1096/fj.202002539R

52. Pizza G, De Vinci C, Lo Conte G, Brasa P, Zuffa S, Melchiorri L, et al. A Human Monoclonal Antibody Detecting a Tumor-Associated Antigen (Taa) Expressed on Several Different Solid Tumors and its Possible Use for Intracavitary Prophylaxis in Non Invasive Bladder Cancer (NIBC). Eur $J$ Of Oncol (2013) 18(2):63-73.

53. Luo W, Ko E, Hsu JCF, Wang XH, Ferrone S. Targeting Melanoma Cells With Human High Molecular Weight-Melanoma Associated AntigenSpecific Antibodies Elicited by a Peptide Mimotope: Functional Effects. J Immunol (2006) 176(10):6046-54. doi: 10.4049/jimmunol.176.10.6046

54. Kohno T, Tam LTT, Stevens SR, Louie JS. Binding Characteristics of Tumor Necrosis Factor Receptor-Fc Fusion Proteins vs Anti-Tumor Necrosis Factor Mabs. J Invest Dermatol Symposium Proc (2007) 12(1):5-8. doi: 10.1038/ sj.jidsymp. 5650034

55. Bortolotti M, Bolognesi A, Battelli MG, Polito L. High in Vitro Anti-Tumor Efficacy of Dimeric Rituximab/Saporin-S6 Immunotoxin. Toxins (2016) 8 (6):192. doi: 10.3390/Toxins8060192

56. Wang LD, Hu Y, Li WJ, Wang F, Lu XS, Han XY, et al. Identification of a Peptide Specifically Targeting Ovarian Cancer by the Screening of a Phage 
Display Peptide Library. Oncol Lett (2016) 11(6):4022-6. doi: 10.3892/ ol.2016.4549

57. Du B, Han HH, Wang ZQ, Kuang LS, Wang L, Yu LP, et al. Targeted Drug Delivery to Hepatocarcinoma In Vivo by Phage-Displayed Specific Binding Peptide. Mol Cancer Res (2010) 8(2):135-44. doi: 10.1158/1541-7786.MCR09-0339

58. Zhou C, Kang JL, Wang X, Wei W, Jiang WY. Phage Display Screening Identifies a Novel Peptide to Suppress Ovarian Cancer Cells In Vitro and In Vivo in Mouse Models. BMC Cancer (2015) 15:889. doi: 10.1186/S12885015-1891-8

59. Rodriguez-Rubio L, Haarmann N, Schwidder M, Muniesa M, Schmidt H. Bacteriophages of Shiga Toxin-Producing Escherichia Coli and Their Contribution to Pathogenicity. Pathogens (2021) 10(4):404. doi: 10.3390/ Pathogens 10040404

60. Maszewska A. Phage Associated Polysaccharide Depolymerases Characteristics and Application. Postepy Higieny I Medycyny Doswiadczalnej (2015) 69:690-702. doi: 10.5604/17322693.1157422

61. Gorecki RK, Bardowski JK. Molecular Mechanisms of Bacteriophage Resistance of Lactic Acid Bacteria. Postepy Mikrobiologii (2011) 50 (4):265-73.

62. Ran B, Yuan YY, Xia WX, Li ML, Yao QC, Wang ZK, et al. A PhotoSensitizable Phage for Multidrug-Resistant Acinetobacter Baumannii Therapy and Biofilm Ablation. Chem Sci (2021) 12(3):1054-61. doi: $10.1039 / \mathrm{d} 0 \mathrm{sc} 04889 \mathrm{e}$

63. Panikar SS, Ramirez-Garcia G, Vallejo-Cardona AA, Banu N, PatronSoberano OA, Cialla-May D, et al. Novel Anti-HER2 Peptide-Conjugated Theranostic Nanoliposomes Combining NaYF4:Yb,Er Nano-Particles for NIR-Activated Bioimaging and Chemo-Photodynamic Therapy Against Breast Cancer. Nanoscale (2019) 11(43):20598-613. doi: 10.1039/ c9nr06535k

64. Gandra N, Abbineni G, Qu XW, Huai YY, Wang L, Mao CB. Bacteriophage Bionanowire as a Carrier for Both Cancer-Targeting Peptides and Photosensitizers and Its Use in Selective Cancer Cell Killing by Photodynamic Therapy. Small (2013) 9(2):215-21. doi: 10.1002/ smll.201202090

65. Mao CB. Photosensitizer-Modified Phage Bionanowires for Selective Cancer Cell Killing. Abstr Pap Am Chem Soc (2014) 247.

66. Sartorius R, D'Apice L, Prisco A, De Berardinis P. Arming Filamentous Bacteriophage, A Nature-Made Nanoparticle, for New Vaccine and Immunotherapeutic Strategies. Pharmaceutics (2019) 11(9):437. doi: 10.3390/pharmaceutics 11090437

67. Borysowski J, Przybylski M, Miedzybrodzki R, Owczarek B, Gorski A. The Effects of Bacteriophages on the Expression of Genes Involved in Antimicrobial Immunity. Postepy Higieny I Medycyny Doswiadczalnej (2019) 73:414-20. doi: 10.5604/01.3001.0013.4081

68. Vaks L, Benhar I. In Vivo Characteristics of Targeted Drug-Carrying Filamentous Bacteriophage Nanomedicines. J Nanobiotechnology (2011) 9 (58). doi: 10.1186/1477-3155-9-58

69. Conte M, Surulescu C. Mathematical Modeling of Glioma Invasion: Acidand Vasculature Me Diate D Go-or-Grow Dichotomy and the Influence of Tissue Anisotropy. Appl Mathematics Comput (2021) 407:126305. doi: 10.1016/J.Amc.2021.126305

70. Motomura K, Chalise L, Ohka F, Aoki K, Tanahashi K, Hirano M, et al. Impact of the Extent of Resection on the Survival of Patients With Grade II and III Gliomas Using Awake Brain Mapping. J Neuro-Oncology (2021) 153 (2):361-72. doi: 10.1007/s11060-021-03776-w

71. Lozinski M, Bowden NA, Graves MC, Fay M, Tooney PA. DNA Damage Repair in Glioblastoma: Current Perspectives on its Role in Tumour Progression, Treatment Resistance and PIKKing Potential Therapeutic Targets. Cell Oncol (2021). doi: 10.1007/s13402-021-00613-0

72. Liu ZD, Zhang W, Cheng XB, Wang HB, Bian L, Wang JL, et al. Overexpressed XRCC2 as an Independent Risk Factor for Poor Prognosis in Glioma Patients. Mol Med (2021) 27(1):52. doi: 10.1186/S10020-021-00316-0

73. Lian QB, Xiao SL, Wang YD, Wang HC, Xie DD. Expression and Clinical Significance of Organic Cation Transporter Family in Glioblastoma Multiforme. Irish J Med Sci (2021). doi: 10.1007/ s11845-021-02675-3
74. Detti B, Scoccianti S, Teriaca MA, Maragna V, Lorenzetti V, Lucidi S, et al. Bevacizumab in Recurrent High-Grade Glioma: A Single Institution Retrospective Analysis on 92 Patients. Radiologia Med (2021) 126 (9):1249-54. doi: 10.1007/s11547-021-01381-5

75. Rombouts MD, Swart EL, Van Den Eertwegh AJM, Crul M. Systematic Review on Infusion Reactions to and Infusion Rate of Monoclonal Antibodies Used in Cancer Treatment. Anticancer Res (2020) 40(3):120118. doi: 10.21873/anticanres. 14062

76. Makki AA, Massot V, Byrne HJ, Respaud R, Bertrand D, Mohammed E, et al. Understanding the Discrimination and Quantification of Monoclonal Antibodies Preparations Using Raman Spectroscopy. J Of Pharm And Biomed Anal (2021) 194:113734. doi: 10.1016/J.Jpba.2020.113734. doi:Artn 113734.

77. Fahey OG, Koth SM, Bergsbaken JJ, Jones HA, Trapskin PJ. Automated Parenteral Chemotherapy Dose-Banding to Improve Patient Safety and Decrease Drug Costs. J Oncol Pharm Pract (2020) 26(2):345-50. doi: $10.1177 / 1078155219846958$

78. Diaz LP, Millan S, Chaban N, Campo AD, Spitzer E. Current State and Comparison of the Clinical Development of Bevacizumab, Rituximab and Trastuzumab Biosimilars. Future Oncol (2021) 17(19):2529-44. doi: 10.2217/fon-2020-0923

79. Carillo S, Jakes C, Bones J. In-Depth Analysis of Monoclonal Antibodies Using Microfluidic Capillary Electrophoresis and Native Mass Spectrometry. J Of Pharm And Biomed Anal (2020) 185:113218. doi: 10.1016/ J.Jpba.2020.113218

80. Pardridge WM. Drug Transport Across the Blood-Brain Barrier. J Of Cereb Blood Flow And Metab (2012) 32(11):1959-72. doi: 10.1038/jcbfm.2012.126

81. Pleiko K, Posnograjeva K, Haugas M, Paiste P, Tobi A, Kurm K, et al. In Vivo Phage Display: Identification of Organ-Specific Peptides Using Deep Sequencing and Differential Profiling Across Tissues. Nucleic Acids Res (2021) 49(7):e38. doi: 10.1093/nar/gkaa1279

82. Gubeli RJ, Bertoldo D, Shimada K, Gerhold CB, Hurst V, Takahashi Y, et al. In Vitro-Evolved Peptides Bind Monomeric Actin and Mimic Actin-Binding Protein Thymosin-Beta 4. ACS Chem Biol (2021) 16(5):820-8. doi: 10.1021/ acschembio.0c00825

83. Ho IAW, Hui KM, Lam PYP. Isolation of Peptide Ligands That Interact Specifically With Human Glioma Cells. Peptides (2010) 31(4):644-50. doi: 10.1016/j.peptides.2009.12.020

84. Cho JH, Kim AR, Kim SH, Lee SJ, Chung H, Yoon MY. Development of a Novel Imaging Agent Using Peptide-Coated Gold Nanoparticles Toward Brain Glioma Stem Cell Marker CD133. Acta Biomater (2017) 47:182-92. doi: 10.1016/j.actbio.2016.10.009

85. Wu CX, Lo SL, Boulaire J, Hong MLW, Beh HM, Leung DSY, et al. A Peptide-Based Carrier for Intracellular Delivery of Proteins Into Malignant Glial Cells In Vitro. J Controlled Release (2008) 130(2):140-5. doi: 10.1016/ j.jconrel.2008.05.015

86. Wang CW, Ning LP, Wang HW, Lu ZJ, Li XG, Fan XY, et al. A PeptideMediated Targeting Gene Delivery System for Malignant Glioma Cells. Int $J$ Nanomed (2013) 8:3631-40. doi: 10.2147/Ijn.S44990

87. Suga T, Watanabe M, Sugimoto Y, Masuda T, Kuroda N, Hagimori M, et al. Synthesis of a High Functionality and Quality Lipid With Gp130 Binding Hydrophobic Peptide for the Preparation of Human Glioma Cell-Targeted PEGylated Liposomes. J Of Drug Delivery Sci Technol (2019) 49:668-73. doi: 10.1016/j.jddst.2018.12.037

88. Patil SS, Railkar R, Swain M, Atreya HS, Dighe RR, Kondaiah P. Novel Anti IGFBP2 Single Chain Variable Fragment Inhibits Glioma Cell Migration and Invasion. J Neuro-Oncology (2015) 123(2):225-35. doi: 10.1007/s11060-0151800-7

89. Liu JK, Lubelski D, Schonberg DL, Wu Q, Hale JS, Flavahan WA, et al. Phage Display Discovery of Novel Molecular Targets in Glioblastoma-Initiating Cells. Cell Death Differ (2014) 21(8):1325-39. doi: 10.1038/cdd.2014.65

90. van Lith SAM, Roodink I, Verhoeff JJC, Makinen PI, Lappalainen JP, YlaHerttuala S, et al. In Vivo Phage Display Screening for Tumor Vascular Targets in Glioblastoma Identifies a Llama Nanobody Against Dynactin-1-P150(Glued). Oncotarget (2016) 7(44):71594-607. doi: 10.18632/oncotarget.12261

91. Roodink I, Franssen M, Zuidscherwoude M, Verrijp K, van der Donk T, Raats J, et al. Isolation of Targeting Nanobodies Against Co-Opted Tumor Vasculature. Lab Invest (2010) 90(1):61-7. doi: 10.1038/labinvest.2009.107 
92. Chen CT, Duan ZQ, Yuan Y, Li RX, Pang L, Liang JM, et al. Peptide-22 and Cyclic RGD Functionalized Liposomes for Glioma Targeting Drug Delivery Overcoming BBB and BBTB. ACS Appl Materials Interfaces (2017) 9 (7):5864-73. doi: 10.1021/acsami.6b15831

93. Dai TC, Jiang K, Lu WY. Liposomes and Lipid Disks Traverse the BBB and BBTB as Intact Forms as Revealed by Two-Step Forster Resonance Energy Transfer Imaging. Acta Pharm Sin B (2018) 8(2):261-71. doi: 10.1016/ j.apsb.2018.01.004

94. Eriste E, Kurrikoff K, Suhorutsenko J, Osokolkov N, Copolovici DM, Jones S, et al. Peptide-Based Glioma-Targeted Drug Delivery Vector Ghope2. Bioconjugate Chem (2013) 24(3):305-13. doi: 10.1021/bc300370w

95. Chen L, Zeng D, Xu N, Li C, Zhang W, Zhu X, et al. Blood-Brain Barrierand Blood-Brain Tumor Barrier-Penetrating Peptide-Derived Targeted Therapeutics for Glioma and Malignant Tumor Brain Metastases. ACS Appl Mater Interfaces (2019) 11(45):41889-97. doi: 10.1021/acsami.9b14046

96. Kolhar P, Anselmo AC, Gupta V, Pant K, Prabhakarpandian B, Ruoslahti E, et al. Using Shape Effects to Target Antibody-Coated Nanoparticles to Lung and Brain Endothelium. Proc Natl Acad Sci USA (2013) 110(26):10753-8. doi: $10.1073 /$ pnas. 1308345110

97. Ksendzovsky A, Walbridge S, Saunders RC, Asthagiri AR, Heiss JD, Lonser RR. Convection-Enhanced Delivery of M13 Bacteriophage to the Brain Laboratory Investigation. J Neurosurg (2012) 117(2):197-203. doi: 10.3171/ 2012.4.JNS111528

98. Nduom EK, Yang CZ, Merrill MJ, Zhuang ZP, Lonser RR. Characterization of the Blood-Brain Barrier of Metastatic and Primary Malignant Neoplasms Laboratory Investigation. J Neurosurg (2013) 119(2):427-33. doi: 10.3171/ 2013.3.JNS122226

99. Souweidane MM, Kramer K, Pandit-Taskar N, Zhou ZP, Haque S, Zanzonico P, et al. Convection-Enhanced Delivery for Diffuse Intrinsic Pontine Glioma: A Single-Centre, Dose-Escalation, Phase 1 Trial. Lancet Oncol (2018) 19(8):1040-50. doi: 10.1016/S1470-2045(18)30322-X

100. Zhan WB, Wang CH. Convection Enhanced Delivery of Liposome Encapsulated Doxorubicin for Brain Tumour Therapy. J Control Release (2018) 285:212-29. doi: 10.1016/j.jconrel.2018.07.006

101. Przystal JM, Waramit S, Pranjol MZI, Yan WQ, Chu G, Chongchai A, et al. Efficacy of Systemic Temozolomide-Activated Phage-Targeted Gene Therapy in Human Glioblastoma. EMBO Mol Med (2019) 11(4):e8492. doi: 10.15252/Emmm.201708492

102. Loset GA, Bogen B, Sandlie I. Expanding the Versatility of Phage Display I: Efficient Display of Peptide-Tags on Protein VII of the Filamentous Phage. PloS One (2011) 6(2):e14702. doi: 10.1371/journal.pone.0014702. doi:ARTN e14702.

103. Rorive S, Belot N, Decaestecker C, Lefranc F, Gordower L, Micik S, et al. Galectin-1 is Highly Expressed in Human Gliomas With Relevance for Modulation of Invasion of Tumor Astrocytes Into the Brain Parenchyma. Glia (2001) 35(2):166-6. doi: 10.1002/Glia.1081

104. Li RH, Ma YB, Hu XC, Wu WJ, Wu XW, Dong CY, et al. [Ru(phen)(2) podppz](2+) Significantly Inhibits Glioblastoma Growth In Vitro and Vivo With Fewer Side-Effects Than Cisplatin. Dalton Trans (2020) 49(26):886471. doi: 10.1039/d0dt01877e
105. Basso J, Miranda A, Sousa J, Pais A, Vitorino C. Repurposing Drugs for Glioblastoma: From Bench to Bedside. Cancer Lett (2018) 428:173-83. doi: 10.1016/j.canlet.2018.04.039

106. Abbruzzese C, Matteoni S, Signore M, Cardone L, Nath K, Glickson JD, et al. Drug Repurposing for the Treatment of Glioblastoma Multiforme. J Exp Clin Cancer Res (2017) 36:169. doi: 10.1186/S13046-017-0642-X

107. Peng CH, Chen ZX, Wang S, Wang HW, Qiu WJ, Zhao L, et al. The ErrorProne DNA Polymerase Kappa Promotes Temozolomide Resistance in Glioblastoma Through Rad17-Dependent Activation of ATR-Chk1 Signaling. Cancer Res (2016) 76(8):2340-53. doi: 10.1158/0008-5472.CAN15-1884

108. Yeh WL, Lin HY, Huang CY, Huang BR, Lin C, Lu DY, et al. MigrationProne Glioma Cells Show Curcumin Resistance Associated With Enhanced Expression of miR-21 and Invasion/Anti-Apoptosis-Related Proteins. Oncotarget (2015) 6(35):37770-81. doi: 10.18632/oncotarget.6092

109. Selle K, Fletcher JR, Tuson H, Schmitt DS, McMillan L, Vridhambal GS, et al. In Vivo Targeting of Clostridioides Difficile Using Phage-Delivered CRISPR-Cas3 Antimicrobials. Mbio (2020) 11(2):e00019-20. doi: 10.1128/mBio.00019-20

110. Nakatsu G, Zhou HK, Wu WKK, Wong SH, Coker OO, Dai ZW, et al. Alterations in Enteric Virome Are Associated With Colorectal Cancer and Survival Outcomes. Gastroenterology (2018) 155(2):529. doi: 10.1053/ j.gastro.2018.04.018

111. Krag DN, Shukla GS, Shen GP, Pero S, Ashikaga T, Fuller S, et al. Selection of Tumor-Binding Ligands in Cancer Patients With Phage Display Libraries. Cancer Res (2006) 66(17):8925-5. doi: 10.1158/00085472.CAN-05-4441

112. Shukla GS, Krag DN, Peletskaya EN, Pero SC, Sun YJ, Carman CL, et al. Intravenous Infusion of Phage-Displayed Antibody Library in Human Cancer Patients: Enrichment and Cancer-Specificity of Tumor-Homing Phage-Antibodies. Cancer Immunol Immunotherapy (2013) 62(8):1397410. doi: 10.1007/s00262-013-1443-5

Conflict of Interest: The authors declare that the research was conducted in the absence of any commercial or financial relationships that could be construed as a potential conflict of interest.

Publisher's Note: All claims expressed in this article are solely those of the authors and do not necessarily represent those of their affiliated organizations, or those of the publisher, the editors and the reviewers. Any product that may be evaluated in this article, or claim that may be made by its manufacturer, is not guaranteed or endorsed by the publisher.

Copyright (C) 2021 Wang, Sheng, Chai, Zhu, Li, Yang, Cui and Ge. This is an openaccess article distributed under the terms of the Creative Commons Attribution License (CC BY). The use, distribution or reproduction in other forums is permitted, provided the original author(s) and the copyright owner(s) are credited and that the original publication in this journal is cited, in accordance with accepted academic practice. No use, distribution or reproduction is permitted which does not comply with these terms. 